\section{Integração de fronteiras: a saúde no contexto de uma política nacional de desenvolvimento}

\author{
Integration of borders: health in the national \\ development policy context
}

\footnotetext{
${ }^{1}$ Vice-Presidência de Produção e Inovação em Saúde, Fundação Oswaldo Cruz, Rio de Janeiro, Brasil. 2 Escola Nacional de Saúde Pública Sergio Arouca Fundação Oswaldo Cruz, Rio de Janeiro, Brasil. ${ }^{3}$ Rede Pan-Amazônica de Cooperação Internacional em Ciência, Tecnologia e Inovação em Saúde Fundação Oswaldo Cruz, Brasília, Brasil.

${ }^{4}$ Rede de Cooperação Intersetorial em Saúde e Desenvolvimento nas Fronteiras, Organização Pan-Americana da Saúde, Brasília, Brasil.

Correspondência C. A. G. Gadelha

Vice-Presidência de Produção e Inovação em Saúde, Fundação Oswaldo Cruz. Av. Brasil 4365,

Rio de Janeiro, $R J$

21040-360, Brasil.

gadelha@ensp.fiocruz.br
}

\section{Abstract}

In recent decades, Brazil's borders with other South American countries have been associated with a negative agenda. Public intervention has aimed almost exclusively at guaranteeing national security through a variety of restrictions. In the current century, with a slow but steady shift in the geopolitical paradigm, integration among South American nations has become a priority. Border regions have now become a strategic area for South American integration and appear as such on the member countries' development agendas. Within this new context, the current study aims to contribute to the connection between the regional health and development agendas, with a focus on border regions, taking a dual approach, by analyzing the development agenda vis-à-vis the field of health and providing clues on how health actions can contribute to a more general perspective of development and integration.

Border Areas; Regional Development; Health Systems
Carlos Augusto Grabois Gadelha 1,2

Laís Costa 3,4

\section{Introdução}

As fronteiras do Brasil com os países da América do Sul foram, nas últimas décadas, associadas a uma agenda negativa de intervenção pública com o intuito quase exclusivo de garantir a segurança nacional por meio da imposição de restrições de toda ordem. Em função disso, nessa região observa-se, em geral, uma precária base produtiva e de infra-estrutura econômica e social que sejam capazes de permitir um processo de desenvolvimento sustentável e integrado. Como conseqüência, esse território se caracteriza por condições sociais e de cidadania bastante adversas, salvo raras exceções sub-regionais.

No presente século, com uma progressiva e lenta mudança no paradigma geopolítico, a integração entre as nações do continente passa a ser vista como prioritária, fruto de um novo contexto político em que diversos presidentes dos países sul-americanos, inclusive do Brasil, passam a manifestar a estratégia de integração como um meio de fortalecimento político e econômico frente ao contexto de uma globalização fortemente assimétrica ${ }^{1}$. A partir dessa percepção, a região de fronteira, como ponto crítico desse processo de integração, deixou de se associar a uma agenda negativa, para configurar uma área estratégica para a integração sul-americana, tendo, desta forma, seu desenvolvimento progressivamente priorizado pelas políticas nacionais. 
O caso da saúde, considerado setor estratégico para o desenvolvimento sustentável, começou a atrair a atenção dos planejadores de políticas voltadas para a integração. Isso refletiu a constatação de que sem um planejamento integrado de saúde nas fronteiras, entraves ao desenvolvimento dessas regiões e dificuldades nos processos de integração regional dificilmente serão superados.

$\mathrm{O}$ aparente paradoxo da "competitividade $\mathrm{x}$ desenvolvimento social", assim como uma maior participação da sociedade civil, marcou, no Brasil, o dilema político das décadas recentes. Emergiu, dessa forma, uma crescente demanda por políticas voltadas para reversão do desfavorável quadro social - com intenções estruturantes, mas, em grande parte, ainda assistencialistas - visando a promover a inclusão social e a eqüidade.

Nos âmbitos regional e territorial, cresce uma percepção de que as diversidades sub-regionais e locais precisam ser consideradas como fundamento para a concepção de formas adequadas de intervenção. A globalização, em vez de implicar a superação do território, modifica e dá origem a novas formas de territorialidade 2 , continuando a existir uma presença essencial das bases locais, regionais e nacionais que configuram teias políticas, sociais e culturais que conformam identidades entre pessoas e destas no espaço. Nessa concepção, as desigualdades regionais deixam de ser reconhecidas apenas no nível macrorregional ou entre países e passam a ser reconhecidas num âmbito talvez ainda mais relevante, que expressa o sentimento de pertencimento e a emergência de identidades entre as pessoas e grupos sociais, sem cair, no entanto, num localismo de reduzida relevância para a concepção de políticas nacionais: o âmbito micro ou sub-regional.

É nesse sentido que o desenvolvimento regional e territorial começa a despontar como uma política norteadora para o desenvolvimento nacional, voltada para a reintegração de espaços e pessoas ao processo de desenvolvimento do país, aproveitando as diversidades observadas como fontes de competitividade e desenvolvimento endógeno em uma economia globalizada.

Nesse contexto histórico e analítico, a faixa de fronteira apresenta-se como uma área prioritária para o desenvolvimento nacional, por ocupar parte expressiva do território brasileiro, pelas precárias condições sociais e de cidadania, por sua biodiversidade, em especial na região amazônica, ou ainda pelo caráter estratégico de fortalecimento de blocos regionais críticos para inserção competitiva da América do Sul na economia mundial. No campo específico da saúde, trata-se de pensar como esta realidade regional impacta na organização do sistema e o papel que a saúde possui num processo mais abrangente de desenvolvimento.

Este artigo objetiva subsidiar a aproximação do campo da saúde com o do desenvolvimento regional, com foco na região de fronteira, procurando caminhar num sentido duplo que, de um lado, traz a agenda de desenvolvimento para o campo da saúde e, de outro, procura dar pistas ou sugestões de como as ações em saúde podem contribuir para uma perspectiva mais geral de desenvolvimento e integração.

\section{Desenvolvimento e saúde}

Atualmente, o setor saúde tem sido considerado como inquestionável indutor e parte constitutiva do modelo de desenvolvimento. O reconhecimento de sua importância é crescentemente reconhecido em diversos campos de pesquisas, ganhando expressão internacional na Organização Mundial da Saúde (OMS), cujos estudos apoiados demonstram a clara relação entre as condições de saúde da população e sua capacidade de desenvolvimento econômico ${ }^{3}$. Além disso, peculiaridades do complexo industrial da saúde, relacionadas ao seu dinamismo, elevado grau de inovação e potencial de geração de renda e emprego o transformam em um conjunto articulado de atividades econômicas que impactam sensivelmente no desenvolvimento econômico e social 4 .

Note-se que, além do impacto sobre a capacidade de desenvolvimento humano e de dinamização da economia, o setor saúde também influencia de forma significativa o conteúdo da abordagem das questões referentes à integração regional e formação de blocos econômicos. Articulado com essa vertente desenvolvimentista, a saúde configura-se como uma das principais áreas a serem planejadas, seja pela necessidade de abordagem e planejamento territorial regional da saúde, seja porque fronteiras epidemiológicas não se restringem a delimitações políticas e institucionais entre países. O planejamento das ações de saúde na fronteira necessariamente coloca a questão das relações com os territórios vizinhos.

Não é de se espantar que em comitês de fronteira e reuniões bilaterais o tema "saúde" seja de abordagem necessária, e normalmente configura-se como um dos grupos de trabalho que mais apresenta demandas e respostas ágeis e um dos que mais evolui (Ministério das Relações Exteriores. Nova Agenda de Cooperação e Desenvolvimento entre Brasil e Uruguai. Documentos da Comissão e Vizinhança Brasil-Colômbia). A urgência do debate desse assunto, assim como 
a impossibilidade de tratá-lo de forma desarticulada entre países fronteiriços trouxe para a pauta do desenvolvimento regional as áreas sociais, com destaque para a saúde, cuja negligência levaria à saturação de qualquer benefício capaz de ser extraído das deliberações e acordos assinados nas relações internacionais entre os países.

\section{Saúde e fronteiras}

Os municípios de fronteira do Brasil têm tido grande dificuldade em prover os seus munícipes de atenção integral à saúde. A falta de recursos humanos especializados, a insuficiência de equipamentos para realização de procedimentos de média e alta complexidade, e a distância entre os municípios e os centros de referência são as principais justificativas apresentadas. Ademais, a dificuldade de planejamento de provisão dessas políticas, em função da população flutuante que utiliza o sistema e que, no caso brasileiro, não é contabilizada para os repasses financeiros do SUS, vem gerando dificuldades diversas cuja principal vítima é o cidadão fronteiriço.

As mesmas dificuldades têm sido observadas nos países fronteiriços com o Brasil, gerando uma movimentação das populações ali residentes em fluxos, ora num sentido ora em outro, na busca de melhor oferta de ações e serviços de saúde. Essa mobilidade tem gerado grandes dificuldades para os gestores de saúde dos municípios brasileiros, bem como para as autoridades dos países vizinhos, além de previsíveis problemas diplomáticos e de saúde pública. Há muito tem se procurado resolver esses problemas sem suficiente êxito, principalmente em função de obstáculos jurídicos e operacionais 5 .

Considerando o caráter político estratégico da melhoria da atenção à saúde e da integração das fronteiras, é que se entendeu que a saúde deve também ser planejada tendo em vista sua qualidade propulsora de desenvolvimento e da integração regional. A solução proposta pelo Brasil foi a de um instrumento voltado para a melhoria da qualidade de vida ao racionalizar a oferta, otimizando a infra-estrutura instalada em seu espaço de cobertura. A idéia era que o Sistema Integrado de Saúde das Fronteiras (SISFronteiras) pudesse também impulsionar o processo de sedimentação da integração regional.

A elaboração do SIS-Fronteiras motivou-se pela percepção de que a morosidade característica dos processos de harmonização, necessários à integração dos distintos e diferenciados sistemas de saúde de países, não é compatível com a necessidade de organização da atenção nas fronteiras. Foi no âmbito do MERCOSUL - da- do o estágio mais avançado de articulação entre países - que essa necessidade foi originalmente recebida pelos governos nacionais, assim como demandas por sugestões para sua equação.

Surgiu a partir da compreensão de que a organização dos serviços nas fronteiras é um processo paralelo e indutor da harmonização necessária à integração dos sistemas. Isso se explica pelo fato de que há, na realidade, uma gama de ações organizativas do sistema que independem do processo de harmonização, o que suscitou o planejamento da integração em horizontes temporais distintos, refletindo, portanto, a observação da importância de ações de transfronteirização, além de harmonização 5 .

Essa é uma questão que merece destaque e deixa claro que quanto mais articulada, institucionalizada e transparente for a evolução e negociação acerca da integração das fronteiras, tanto mais se contribuirá para o alcance da visibilidade e apoio político necessários para o início do planejamento das políticas nacionais voltadas para a integração de fronteiras.

A partir daí surgiu a proposta do SIS-Fronteiras, voltado para a integração da saúde com os dez países sul-americanos que fazem fronteira com o Brasil, refletindo o fato de que as dificuldades quanto à prestação de saúde nas fronteiras não se restringem aos países do MERCOSUL. Essa iniciativa visava não somente à melhoria da qualidade de vida da população, como principalmente subsidiar o processo de harmonização de saúde entre os países, necessário para o estabelecimento de marcos legais para a integração, otimização e qualificação da atenção prestada nas fronteiras.

O debate sobre a situação da saúde nas fronteiras acontece há muito tempo, porém, seja pela falta de ordenação das iniciativas ou pela formulação de estratégias de caráter apenas pontual, a situação permaneceu praticamente inalterada. Dois foram os principais empecilhos ao processo de integração históricos das ações de saúde nas fronteiras: o atrelamento das soluções ao desenvolvimento do processo de harmonização e a concentração do tema no controle do acesso e compensação financeira 5 .

Ainda que seja inegável a importância da composição do financiamento para a definição do perfil da integração dos sistemas, este é um passo que demanda base de dados compartilhada, fluxos pactuados e harmonizações políticas claras e concretas. Por outro lado, há diversas iniciativas que podem ajudar na compatibilização dos sistemas de informação e na articulação de serviços prestados, e que servem como base para a definição de regras em processo mais amplo e definitivo de harmonização dos sistemas. 
Foi entendido, dessa forma, que o processo de integração de ações de saúde nas fronteiras deverá contemplar horizontes temporais distintos, combinando ações de transfronteirização com ações de harmonização.

A proposta era de que a política aconteceria em etapas distintas, sendo a primeira o Programa de Adesão ao Pacto pela Qualificação da Saúde nas Fronteiras, visando: (1) a identificar, planejar e regulamentar as ações hoje realizadas. Ao formalizar a situação existente e mapear os usuários do sistema, busca-se induzir a organização do sistema; (2) a financiar as ações já existentes: aumentar o teto financeiro dos municípios, condicionando este aumento à adesão ao SISFronteiras; e (3) a criar canais de disseminação sistemática das diversas iniciativas relacionadas às fronteiras, instrumento importante de aprendizado para a gestão local 6 .

A idéia é iniciar uma política de incentivo à gestão, a partir do repasse de recursos financeiros para os municípios de fronteira que, em contrapartida, estarão participando ativamente da elaboração de um diagnóstico da realidade de saúde local e obrigados a realizar cadastro integral de sua população no cartão SUS.

Esse adicional de repasse financeiro acontecerá em fases distintas, a primeira refere-se ao Diagnóstico e Plano de Ação, a partir da criação de incentivo específico para as ações de integração, denominado Incentivo à Implantação do Sistema Integrado de Saúde das Fronteiras, que representa $30 \%$ do total de recursos disponibilizados para o SIS. O gestor se responsabilizará pelas ações correspondentes ao Pacto pela Qualificação da Saúde nas Fronteiras, seguindo as diretrizes de identificação, qualificação, reorganização e regulamentação do atendimento para os municípios que aderirem ao programa de integração dos serviços de saúde das regiões fronteiriças 6 .

A segunda fase refere-se à implantação de serviços nas regiões de fronteiras, englobando $35 \%$ do montante de recursos previstos para a implantação dos serviços essenciais e garantia de acesso aos serviços especializados. Cabe ressaltar que, nesse primeiro momento, o incentivo não visa a financiar o sistema, mas promover sua integração. A definição dos serviços deverá se dar mediante deliberação pelo grupo tripartite de acompanhamento e avaliação, sempre considerando as características e demandas locais 6 .

A política do SIS-Fronteira define que como requisito mínimo para implantação de serviços, considerar-se-á a cobertura, para $100 \%$ da população, de serviços de atendimento ambulatorial básico, incluindo o primeiro atendimento às urgências. Para a garantia do acesso aos serviços especializados, deve-se definir no rol de serviços possíveis, os pertinentes e necessários, podendo viabilizar o acesso aos serviços de saúde localizados na linha de fronteira ou serviços de referência localizados em outros municípios 6 .

A terceira fase refere-se à qualificação da gestão em áreas consideradas estratégicas. A distribuição dos recursos "dependerá de avaliação das situações apontadas no plano operacional quanto à configuração final da estrutura dos serviços, capacidade institucional local, perfil epidemiológico da população, qualidade e sustentabilidade da atenção e abrangência do Programa para Qualificação da Gestão. Nesta fase, o financiamento poderá ser dirigido não somente aos municípios, mas também aos estados" 6 (p. 47).

Na prática, um diagnóstico que não seja capaz de apontar fluxos de referência e contrareferência e que não considere a natureza das demandas dos usuários dos países vizinhos não proporciona qualificação mínima para as informações necessárias. Ademais, diagnósticos realizados somente pelos municípios da linha de fronteira, que são aqueles contemplados por essa política, não terão o caráter regionalizado necessário. Adicione-se a isso o fato de que o sucesso dessa política depende da incorporação de visão estratégica para o desenvolvimento do sistema, entendendo que, em muitos casos, o investimento integrado com os países vizinhos é a melhor forma de organizar o sistema de saúde regionalizado e desta forma melhorar a forma de vida das populações das regiões de fronteira.

Quando da criação da política, o Ministério da Saúde reconheceu a insuficiência de informações para a elaboração de um sistema que permitisse a integração de determinadas ações de saúde nas fronteiras. Resolveu desenhar essa primeira etapa de reconhecimento e equação da situação emergencial para, a posteriori, definir com as três esferas de governo como minimizar os impactos da utilização do sistema por parte dos estrangeiros, processo este que deveria ocorrer em paralelo com negociação entre os demais países, de forma a garantir reciprocidade nas relações de oferta e demanda dos serviços prestados.

Alguns avanços têm sido alcançados no tocante à elaboração de diagnósticos de saúde para municípios da linha de fronteira, mas ainda não se consegue verificar o relacionamento deste diagnóstico, da infra-estrutura instalada e real utilização do sistema por parte da população flutuante que o utiliza. Para reverter essa situação muito há que se avançar na coordenação de políticas de fronteiras no Brasil, assim como em sua articulação com as dos países vizinhos. Nesse sentido recai sobre o Programa de Desenvolvimento da Faixa de Fronteira (PDFF), coordenado hoje pelo Ministério da Integração Nacional, e 
demais ações de cunho regional, a responsabilidade pelo avanço e estabelecimento da região fronteiriça como uma região prioritária para o país, permitindo articular saúde e desenvolvimento.

\section{A Política Nacional de Desenvolvimento Regional e o Programa de Desenvolvimento da Faixa de Fronteira}

A necessária coesão social e econômica no território nacional aponta para a demanda de uma política nacional que promova o desenvolvimento territorial. Fato apontado pela Política Nacional de Desenvolvimento Regional (PNDR), que enfatiza o círculo vicioso do fluxo de investimentos no Brasil: "as atividades econômicas dinamizam-se em áreas que apresentam melhores condições de atração locacional (...) que contam, entre outros, com atributos vantajosos de infraestrutura, com recursos humanos qualificados e qualidade de vida da população aceitável (...), [enquanto] áreas excluídas pelo mercado (...) tendem a permanecer à margem dos fluxos econômicos principais e, assim, apresentar menores níveis de renda e bem-estar, o que termina por instigar o esvaziamento populacional e os fluxos migratórios para áreas mais dinâmicas ou de maior patrimônio produtivo instalado" 7.

É neste contexto que o desenvolvimento regional volta a ser um tema na agenda do Brasil, reflexo do cenário global em que o fortalecimento regional passa a afetar diretamente o desenvolvimento das potencialidades locais, determinando, em grande parte, a inserção competitiva do país no mercado global. Vale enfatizar a necessidade de que seja incluído o caráter multidimensional que influencia a competitividade sistêmica na implementação de políticas regionais, considerando aspectos econômicos, políticos, culturais e sociais 8 . A grande inovação introduzida pela $\mathrm{PN}$ DR refere-se à abordagem dirigida a espaços subregionais, buscando a dinamização econômica, o fornecimento de infra-estrutura econômica e social e a melhoria nas condições de cidadania. Com essa perspectiva, deve necessariamente envolver o fortalecimento dos atores locais e o aproveitamento das peculiaridades da organização social e das características produtivas locais.

Em sua abordagem de múltiplas escalas, verificou-se a necessidade de implementar programas específicos para o desenvolvimento de algumas áreas especiais, sendo a Faixa de Fronteira um desses casos que, de acordo com a PNDR, "suscitam estratégias específicas de desenvolvimento" 9 (p. 30-1). O desenvolvimento da Faixa de Fronteira surge, dessa forma, não somente co- mo importante ferramenta do desenvolvimento nacional como também da política internacional brasileira, uma vez que se configura como região de visível potencialidade de catalisar a integração sul-americana.

Ainda que a percepção da necessidade de atuação na região, por parte dos documentos de diretrizes políticas nacionais, seja relevante, e represente sério avanço em relação ao descaso em que a região fronteiriça vem sendo relegada, está longe de ser definitiva para o desenvolvimento sustentável da Faixa de Fronteira. Na realidade, não há tradição de atuação nessa região. Os problemas peculiares a ela são pouco conhecidos e de difícil solução, uma vez que se depara com barreiras diplomáticas, legais e mesmo burocráticas. A própria natureza da demanda é desarticulada, e, portanto, sem força política. Além dessas dificuldades, o desconhecimento do que é a Faixa de Fronteira, sua dinâmica, potencialidades e diversidade, dificulta a atuação dos governos estaduais e federal. Quanto aos governos municipais, estes normalmente são mal-aparelhados e apresentam volume de arrecadação que não permite a promoção de relevantes mudanças no cenário local. Ademais, em muitas fronteiras brasileiras, populações vizinhas flutuantes invadem os serviços e utilizam bens públicos disponibilizados, dada a inexistência ou falta de qualidade em seus próprios países, fato recorrente no setor saúde, em que a universalidade do SUS configura-se, em muitos casos, como a única opção de atenção à saúde para os munícipes de países vizinhos.

Uma vez que os critérios de repasses de recursos federais para municípios e Estados não contemplam a utilização dos serviços por essa população flutuante, o sistema público local, na fronteira, fica onerado e normalmente perde qualidade, prejudicando sobremaneira uma população já desprovida de infra-estrutura básica, tanto social, quanto física. Isso reforça ainda mais a importância de uma PNDR, justamente pela sua capacidade de reverter tendências tradicionais de concentração da produção e renda no espaço, e, portanto, de tratar de forma diferenciada espaços abandonados pelo Estado nas últimas décadas.

Apesar de ser estratégica para a integração sul-americana, uma vez que faz fronteira com dez países do continente, de corresponder à aproximadamente $27 \%$ do território nacional (11 Estados e 588 municípios) e reunir cerca de 10 milhões de habitantes, a faixa de fronteira configura-se como uma região pouco desenvolvida, historicamente abandonada pelo Estado e marcada pela dificuldade de acesso a bens e serviços públicos, pela falta de coesão social e pela inobservância de condições de cidadania. 
Na prática, a criação de uma Faixa de Fronteira, estabelecida atualmente em $150 \mathrm{~km}$ de largura paralela à linha divisória terrestre do território nacional, foi motivada por ser esta uma área estratégica para a segurança nacional, resultante de uma política que deu ênfase à concepção de fronteira como sendo uma peça fundamental para a defesa, com características de imposição de barreiras às ameaças externas e estabelecimento de limites nas relações com os países vizinhos. De acordo com a Constituição Federal de 1988, em seu artigo 20, $\$ 2^{\circ}$, "A faixa de até cento e cinqüenta quilômetros de largura, ao longo das fronteiras terrestres, designada como faixa de fronteira, é considerada fundamental para defesa do território nacional, e sua ocupação e utilização serão reguladas em lei". A lei que dispõe sobre a faixa de fronteira é a Lei $n^{\circ}$. 6.634 de 2 de maio de 1979, regulamentada pelo Decreto Lei $n^{o} .85 .064$ de 26 de agosto de 1980.

Como resultado, observa-se na região, ocupação limitada, inexistência ou pouca eficiência e alto custo para a provisão de bens e serviços públicos, além de dificuldades diversas no planejamento de políticas regionais. Os objetivos pregressos não contemplaram o desenvolvimento sustentável, a qualidade de vida da população e a promoção de cidadania, e como resultado desta negligência, esta região, que abrange pouco mais que um quarto do território nacional, configura-se, em termos gerais, como uma região deprimida, marcada por profundas iniqüidades, estas agravadas por questões diplomáticas peculiares a territórios contíguos entre duas ou mais nações.

O reconhecimento da importância da Faixa de Fronteira, enfatizada pela PNDR, trouxe consigo a necessidade de rever as políticas incidentes na região. Suscitou-se, então, a necessidade de reformulação do programa de governo que atua sobre a região, o Programa de Desenvolvimento da Faixa de Fronteira. Esse Programa foi criado em 1955, com o nome de Programa de Auxílio Financeiro aos Municípios da Faixa de Fronteira (PAFMFF) e foi recepcionado pela Lei $n^{\circ}$. 6.634. Sua proposta, nestes últimos anos, foi a de contribuir para o desenvolvimento social da faixa de fronteira, de forma a fixar o homem na terra e auxiliar para a reversão do processo de êxodo rural que começou a configurar-se como sério problema nas grandes metrópoles. Mas, desde a sua criação, tem sido voltado para a questão da defesa, da soberania e segurança nacional, com diretrizes que ainda não observavam o necessário desenvolvimento econômico e social. A atuação contemplava uma agenda essencialmente negativa, não observando as potencialidades endógenas e as diversidades regionais.
Desde a sua criação, o Programa caracterizava-se por atuação fragmentada e norteada por demandas políticas pontuais cuja atenção dava-se integralmente por intermédio de emendas parlamentares. O PDFF, cuja gerência foi incumbida ao Ministério da Integração Nacional a partir de novembro de 1999, caracterizava-se por uma lógica assistencialista, sem qualquer planejamento ou orientação programática, resultando na dispersão dos escassos recursos públicos, sem ter impactos na geração de emprego e renda, na organização da sociedade civil e na estruturação das atividades produtivas. O padrão de intervenção supracitado ressentia justamente da falta de diretriz de uma política nacional, gerando duplicações de iniciativas, competições predatórias, falta de planejamento integrado do desenvolvimento territorial e visão estratégica quanto ao aproveitamento das potencialidades endógenas.

Para a reestruturação da intervenção sobre a faixa de fronteira, o primeiro passo deveria ser o conhecimento de suas particularidades, considerando que a falta de informações sistematizadas sobre essa região dificulta qualquer planejamento mais estruturado das ações nas fronteiras que respeite sua elevada diversidade econômica, política, cultural e institucional. Nessa situação, talvez a principal iniciativa recente do governo federal para uma ação articulada na região foi a promoção de um estudo por parte de um dos mais conceituados grupos de pesquisa do país no tema, liderado pela professora Lia Osório Machado, visando, a partir das diversidades econômicas e culturais existentes, a propor uma sub-regionalização da Faixa de Fronteira que permitisse nortear a ação pública 10. A partir dessa contribuição, foi adotada pelo programa a regionalização da Faixa de Fronteira em três grandes arcos (Norte, Central, Sul) e 17 sub-regiões, considerando similaridades e complementaridades no tocante à articulação dos municípios, características culturais, históricas, étnicas, demográficas, potencialidades econômicas, infra-estrutura instalada, entre outras.

Seguindo o estudo citado, o arco norte abrange a Faixa de Fronteira do Estado do Amapá até o Acre. Diferenças na base produtiva, posição geográfica e predomínio de população indígena foram os principais critérios para a definição das sub-regiões do arco. Apesar dos fluxos migratórios procedentes de outras regiões do país (principalmente nordestina), a faixa de fronteira norte constitui um "arco indígena", com grandes áreas de reserva e identidade territorial ligada à sua importância étnico-cultural. A identidade produtiva da maioria das sub-regiões do arco norte se baseia na pesca, no extrativismo vegetal e no cultivo da mandioca. Há alguns focos de mine- 
ração, silvicultura e produção de piaçava, além de criação de bovinos. Mas grande parte das atividades produtivas que geram emprego e renda no arco norte tem base urbana, caracterizada por mão-de-obra desqualificada e mal-remunerada. Junte-se a isso as dificuldades de comunicação e circulação entre as cidades, que é um fator inibidor para investidores potenciais.

Note que o arco norte está integralmente na região amazônica, configurando-se, desta forma, por uma dupla prioridade da PNDR. Como principais problemas dessa região podem-se listar as questões fundiárias, em especial nas áreas em que há menor povoamento e conexão com o país vizinho, exploração indevida dos recursos naturais e biopirataria. E, em especial nos territórios que fazem fronteira com Bolívia, Peru e Colômbia, pelo fato do Brasil ter maior conectividade com estes países vizinhos, em função da circulação fluvial, observa-se influência de tráfico e de atividades ilícitas diversas 11, assim como, particularmente com a Bolívia, há grande fluxo populacional utilizando serviços de saúde do lado brasileiro.

O arco norte é marcado também pelo seu potencial inexplorado, em função especialmente da interligação com a América Central, da saída para o Pacífico e da biodiversidade. Note que o potencial para o desenvolvimento de fitoterápicos, mercado crescente no mundo, é sub utilizado no Brasil e não somente aumentaria o acesso da população mais carente aos medicamentos, como também impulsionaria a indústria farmacêutica, hoje responsável por déficit crescente nas transações comerciais brasileiras 4 .

$\mathrm{O}$ arco central abrange a Faixa de Fronteira nos Estados de Rondônia, Mato Grosso e Mato Grosso do Sul. Oito sub-regiões foram identificadas, um indicador de grande diversidade nos tipos de organização territorial. De acordo com o estudo, a unidade do arco deriva do caráter de transição entre a Amazônia e o Centro-Sul do país e de sua posição central no subcontinente. É nele que se encontram as duas grandes bacias hidrográficas sul-americanas: a Bacia Amazônica e a Bacia do Paraná-Paraguai. Pode-se caracterizar a base da organização do sistema produtivo em produção agrícola, criação de gado e em um modelo industrial-comercial ligado à agroindústria englobando redes de secagem e armazenamento de soja, além de frigoríficos de carne bovina e pescado. Na linha de fronteira e adjacências desse arco, que faz fronteira com a Bolívia e Paraguai, caracteriza-se também forte atividade de contrabando e turismo sexual 10 .

Essas são atividades ainda marcantes ao longo da fronteira, mas no arco central, em particular, apontam-se as dificuldades de substituição dessas atividades ilícitas, cujo inquestionável efeito sobre o tecido social e qualidade de vida são negativos e muitas vezes aparecem como uma das poucas possibilidades de inserção econômica das pessoas da região. Os governos locais e estaduais envolvidos têm encaminhado propostas ao governo federal na busca de investimentos e planejamento estruturado para a substituição da atividade ilícita em questão, visando a evitar dano social e econômico à população resistente. Na prática, entretanto, esses apelos não têm sido atendidos, em função dos escassos recursos disponíveis para a região. De acordo com Bandeira 8 (p. 78), políticas cujo foco de atuação sejam o território precisam viabilizar "a reconversão produtiva das regiões elou segmentos negativamente afetados".

Como potencialidades, tanto o eixo de Rondônia, seguindo até Guajará-Mirim do lado brasileiro, em função do projeto de instalação das Usinas de Santo Antonio e Jirau, do Complexo do Rio Madeira, quanto o eixo do Mato Grosso do Sul, passando por Corumbá - eixo de integração Bolívia: Corredor Vial de Integración Santa Cruz - Puerto Suárez, vêm sendo priorizados por organismos de fomento à integração e ao desenvolvimento, como o Banco Inter-Americano de Desenvolvimento (BID), Ministério Britânico para o Desenvolvimento Internacional (DFID), Corporação Andina de Fomento (CAF) e Banco Nacional de Desenvolvimento Econômico e Social (BNDES), com grande fluxo de investimentos sendo aplicado no segundo caso, e proposto, no primeiro, o que deveria ser aproveitado para o estabelecimento de eixos de desenvolvimento nas áreas citadas. Note que há demandas decorrentes das necessidades da matriz energética brasileira que estão induzindo investimentos de grande escala, o que poderá levar a um crescimento descoordenado, assim como deslocamentos de populações que terão ainda maior dificuldade de se inserirem em novos mercados.

Por fim, o arco sul compreende a faixa de fronteira dos Estados do Paraná, Santa Catarina e Rio Grande do Sul. É essa região onde se encontra uma das fronteiras mais permeáveis e de interações mais intensas com os países vizinhos, e que estão sendo reestruturadas com a criação do MERCOSUL, e até, posterior a isto, a partir das relações bilaterais estabelecidas entre os países. O estudo mostra que o legado da imigração européia é uma das marcas fundamentais da sociedade e da economia regional, caracterizada por uma estrutura fundiária moldada por pequenas e médias propriedades, com base produtiva voltada para a agroindústria e criação de gado bovino e ovino. Mais recentemente, a expansão ter- 
ritorial do cultivo da soja e desenvolvimento de uma compacta rede urbana conectada por densa malha rodoviária impulsionaram a indústria voltada para os agronegócios interno e externo. As interações transfronteiriças são fortemente regidas pela expansão de interesses e de imigrantes brasileiros, ligados à rizicultura no Uruguai e à soja no Paraguai.

Sendo essa a porção da fronteira brasileira com maior interconexão com os países vizinhos, assim como com maior conexão regional, ditada pela formação do MERCOSUL, não surpreende que ali se encontrem as principais iniciativas em termos de integração de fronteiras. Destacam-se as relações estabelecidas na fronteira com o Uruguai, a partir da Nova Agenda de Cooperação e Desenvolvimento Fronteiriço Uruguaio-Brasileira 12 já em vigor, e da fronteira com a Argentina, que recentemente assinou Acordo sobre Comunidades Fronteiriças Vinculadas (Ministério das Relações Exteriores. Iguaçu + 20. Dia da Amizade Brasil-Argentina. Fundação Alexandre de Gusmão; 2005). Essas iniciativas, de um lado, representam desafios para alterar os padrões de especialização dos países e regiões do arco sul e, de outro lado, colocam diversas potencialidades de dinamização da região pela exploração, ainda tímida, de complementaridades no âmbito do MERCOSUL.

A Figura 1 fornece uma visão geral dos três arcos e das sub-regiões caracterizadas neste primeiro esforço de regionalização, devendo nortear as diferenciadas formas de intervenção para a Faixa de Fronteira como região de desenvolvimento.

Tomando essa regionalização como base, o PDFF tem como objetivo principal promover o desenvolvimento da Faixa de Fronteira por meio de sua estruturação física, social e econômica, com ênfase na ativação das potencialidades locais e na articulação com outros países da América do Sul. Além desses, vale ressaltar seus objetivos associados que se referem à promoção da convergência das políticas públicas setoriais na Faixa de Fronteira, visando a: (a) enfrentamento das desigualdades intra e inter-regionais, considerando a diversidade sócio-econômica e cultural da região; (b) articulação da questão da soberania nacional com o desenvolvimento regional, em sua dimensão econômica, social, institucional e cultural; (c) promoção das potencialidades endógenas, em diversas escalas espaciais, voltada para a inserção social e econômica das populações locais; (d) articulação dos investimentos em infra-estrutura econômica e social para apoiar o processo de integração nacional; (e) e estímulo aos investimentos em arranjos e cadeias produtivas prioritários para o desenvolvimento sustentável de regiões menos dinâmi- cas, buscando a otimização dos benefícios sociais deles decorrentes, o desenvolvimento local e a integração da América do Sul.

O programa está, entretanto, muito distante de alcançar esses objetivos, o que se deve em função de diversos fatores, entre eles a não tradução das prioridades políticas em recursos orçamentários. Em 2005, por exemplo, o programa foi contemplado com recursos orçamentários propostos diretamente pelo poder executivo de apenas R \$ 5,5 milhões (Ministério do Planejamento, Orçamento e Gestão. Orçamento Geral da União; 2005), mantendo-se a maior parte dos recursos provenientes de emendas parlamentares, que ainda seguem, predominantemente, uma lógica fragmentada, assistencialista e sem maiores vínculos com estratégias de desenvolvimento de regiões particulares. Frente a esse quadro de absoluta insuficiência de recursos, pode-se afirmar que o avanço ocorrido se ateve principalmente na proposta de um novo referencial conceitual e normativo, não chegando a transformar concretamente a situação da região e o padrão público de intervenção.

Mesmo a base legal existente ainda se mantém praticamente inalterada, reforçando o caráter restritivo das ações para as fronteiras. A revisão do marco regulatório é condição essencial para o estabelecimento da necessária parceria público-privada para o desenvolvimento regional da Faixa de Fronteira e, principalmente, para os investimentos de maior porte, necessários para a integração da infra-estrutura existente. Ademais, sem a devida harmonização dos marcos regulatórios sul-americanos, não haverá ambiente propício para avanço na integração dessa região. Conforme enfatizado por Gartenkraut 13 (p. 20) "[h]á, em todos os países da região, (...) [os] 'transitórios institucionais', entendidos como marcos legais e regulatórios incompletos e/ou não-validados, situação que se caracteriza por estágios diferenciados por setor e por país. Tal situação eleva o grau de incerteza para os investidores e a sua percepção de risco".

No Brasil, a Lei $n^{o}$. 6.634, que dispõe sobre a faixa de fronteira, tem foco exclusivo sobre questões de segurança nacional. Essa Lei, de 1979, portanto do período em que o País encontrava-se em regime de exceção, encontra-se desatualizada em relação às diretrizes para o desenvolvimento da Faixa de Fronteira. Essa incompatibilidade entre as diretrizes políticas e o arcabouço legal tem impedido não somente fluxos de investimentos interessantes para a região como também relegado à informalidade diversas ações que poderiam fortalecer o processo de integração, não incorporando minimamente a integração ou mesmo o fortalecimento da cidadania. 


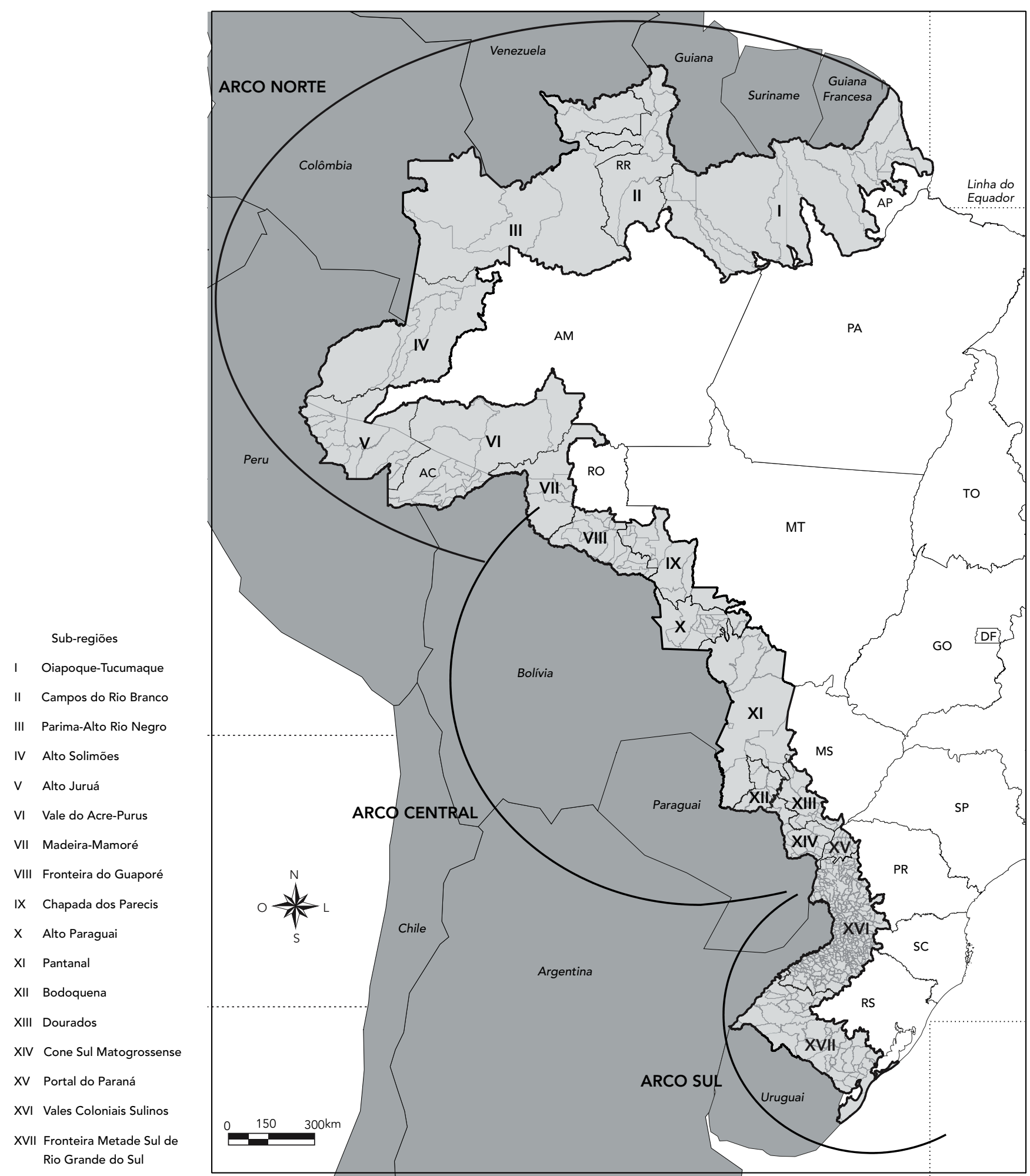

Fonte: Machado 11 
As diretrizes de integração sul-americanas vêm sendo contempladas em alguns acordos bilaterais, mas o fato é que as leis de fronteira não se comunicam, e encontram-se fragmentadas em textos constitucionais, infraconstitucionais e acordos diversos. Na realidade, há graves lacunas políticas e de informações sobre em que grau e medida e necessidade cada zona de fronteira poderia avançar. Sem a superação dessa lacuna, o processo de integração de fronteiras continuará incorrendo na informalidade característica impeditiva do planejamento e avaliação das ações empreendidas.

No Brasil, a formação de grupos de trabalho interministeriais, coordenados pela Presidência da República (dois, entre 2004 e 2005), faz supor que já é consensual a necessidade de atualização/substituição da Lei $n^{\circ}$. 6.634/1979. Pela complexidade do tema e falta de informações suficientes, entre razões diversas, esses grupos foram extintos sem ter sucesso em sua empreitada. Em síntese, ainda falta uma base de organização das sociedades locais para exercer a pressão social e política necessária para uma profunda e indispensável revisão do marco regulatório da faixa de fronteira.

No nível incipiente de um novo padrão de intervenção, o programa traçou uma estratégia de atuação que gira em torno de duas grandes linhas de ação:

1) Desenvolvimento integrado das cidades-gêmeas, voltado para as diretrizes do governo federal de dar primazia ao desenvolvimento, à cidadania e à integração sul-americana, já se observando ações integradas em 5 das 27 cidades-gêmeas da fronteira, como experiências piloto de integração que cobrem os três arcos da fronteira, a saber: Tabatinga/Amazonas - Letícia/Colômbia, Ponta Porã/Mato Grosso do Sul - Pedro Juan Caballero/Peru, Santana do Livramento/Rio Grande do Sul - Rivera/Uruguai, Dionísio Cerqueira/Santa Catarina e Barracão/Paraná - Bernardo de Irigoyen/Argentina e Uruguaiana/Rio Grande do Sul - Paso de los Libres/Argentina.

2) Fortalecimento da sociedade civil mediante a promoção da articulação dos atores em fóruns de desenvolvimento e incentivos à dinamização econômica e social de algumas mesorregiões mais estruturadas da fronteira: grande fronteira do MERCOSUL/Paraná-Santa Catarina-Rio Grande do Sul e Metade Sul do Rio Grande do Sul/Rio Grande do Sul, no arco sul e Alto Solimões/Amazonas e Vale do Rio Acre/Acre-Amazonas, no arco norte.

Essas ações desenhadas no bojo do PDFF passam a ganhar uma nova perspectiva, como ação transversal de governo, com a criação da Câmara de Políticas de Integração Nacional e De- senvolvimento Regional, pelo Decreto $n^{\circ} .4 .793$ de 23 de julho de 2003, tendo sido instalada no dia 1 de junho de 2004. Essa iniciativa materializa uma institucionalidade que permite avançar na concretização do desenvolvimento regional como uma área de intervenção que requer uma ação multisetorial. Configura-se como passo inicial importante para a consecução de uma ação integrada com foco territorial pela sinergia proporcionada, pela articulação das ações de governo federal e pelo fortalecimento do pacto federativo, ainda frágil, porém fundamental para que políticas estruturantes como a PNDR 7, ou para que programas como o PDFF tenham melhores condições de alcançar seus objetivos.

A Câmara constituiu um Grupo de Trabalho Interministerial (GTI) no segundo semestre de 2004, composto por 23 Ministérios e Secretarias Especiais, coordenado pela Secretaria de Programas Regionais do Ministério da Integração Nacional, visando à articulação concreta das iniciativas do governo, de modo a promover sinergias, aproveitar complementaridades e proporcionar desenvolvimento e sustentabilidade das políticas implementadas. As políticas definidas no âmbito desse grupo são priorizadas de acordo com os programas e ações existentes no Plano Plurianual (PPA) do Governo Federal e com as necessidades, gargalos e potencialidades locais 14 .

O PDFF, priorizado no âmbito dessa iniciativa, passa, ao menos potencialmente, a ter condições concretas de contribuir para uma mudança qualitativa no desenvolvimento da região. Com isso, abre-se uma nova perspectiva de fortalecer e catalisar as linhas de atuação do PDFF, ao articular a ação do Governo Federal na dinamização econômica, na infra-estrutura social e econômica e na organização social e institucional. O grande mérito dessa ação é sua atuação integrada dentro do governo federal, e com as demais esferas governamentais e sociedade civil, almejando a sustentabilidade da intervenção pública e a criação de um novo paradigma de desenvolvimento regional. Na prática, essa Câmara conseguiu convergir, em 2005, recursos da ordem de R $\$ 774$ milhões para as mesorregiões priorizadas situadas na Faixa de Fronteira - fruto da soma de 219 iniciativas ministeriais - e de R\$ 61 milhões para as cinco cidades-gêmeas citadas, envolvendo 157 iniciativas dos ministérios participantes 14 .

Entretanto, a despeito da alta relevância dessa iniciativa de ação integrada, ela ainda se configura muito mais como uma primeira organização e sistematização de informações existentes segundo um foco territorializado - o que certamente é de extrema importância -, não representando, até o presente, uma mobilização expressiva de recursos que envolva o aproveitamento concre- 
to de sinergias e complementaridades. Mesmo a institucionalização dessas estruturas integradas ainda se mostra bastante precária, podendo, a qualquer momento, se perder todo o esforço realizado em virtude de movimentos conjunturais das políticas e dos dirigentes.

Em resumo, a despeito do avanço atingido, o desenvolvimento regional ainda não possui uma institucionalidade que permita caracterizar a intervenção como uma ação federativa e pactuada de Estado. Para a Faixa de Fronteira, o que se observa, a exemplo do que ocorre no campo da saúde, é a existência de políticas "na” fronteira e não de políticas "de" fronteira realmente integradas no campo nacional e internacional.

\section{Consideração final}

A análise efetuada neste artigo mostra que a visão da região de fronteira está passando por uma profunda e importante transformação, deixando, progressivamente, de ser concebida como uma região-problema, para a qual são impostas uma série de restrições, para se constituir numa região prioritária para o desenvolvimento regional. Se bem que, na prática, as ações sejam ainda incipientes, é a partir desse novo paradigma que as políticas públicas começam a ser organizadas. Nesse contexto, a área da saúde possui um papel de destaque. Por um lado, a saúde constitui um importante e vital vetor de integra- ção entre a sociedade e os cidadão fronteiriços, possuindo um papel estratégico para a PNDR e para a estratégia de integração do continente. Por outro lado, o sucesso das ações de saúde na fronteira depende fortemente da articulação política e institucional do Governo Federal e em âmbito federativo. $\mathrm{O}$ tratamento das questões relacionadas às relações internacionais no âmbito da América do Sul, a dinamização econômica de espaços excluídos ou estagnados, o combate integrado à violência, a criação de alternativas estruturantes de inclusão social, a revisão do marco regulatório, a alteração da noção de segurança nacional, as ações integradas de educação, entre muitas outras políticas, se mostram essenciais para que as políticas de saúde tenham sucesso na região.

Assim sendo, a análise desenvolvida neste artigo remete, em última instância, para a necessidade de articular a saúde com uma política nacional de desenvolvimento, com ênfase, no caso tratado, para a região de fronteira e para o novo papel do espaço sul-americano como uma base de desenvolvimento. Os desafios são imensos, mas este talvez possa se constituir num dos grandes marcos para a consolidação de uma visão não setorial da saúde, evidenciando sua relação com as condições de vida dos cidadãos brasileiros e daqueles dos países vizinhos que compartilham, em grande medida, de nossos problemas e de nossas possibilidades de superação das condições de atraso e de subdesenvolvimento. 


\section{Resumo}

As fronteiras do Brasil com os países da América do Sul foram, nas últimas décadas, associadas a uma agenda negativa de intervenção pública com o intuito quase exclusivo de garantir a segurança nacional por meio da imposição de restrições de toda ordem. No presente século, com uma progressiva e lenta mudança no paradigma geopolítico, a integração entre as nações do continente passa a ser vista como prioritária. A região de fronteira, como ponto crítico desse processo de integração, passa a configurar uma área estratégica para a integração sul-americana, entrando na agenda de desenvolvimento dos Estados nacionais. Nesse novo contexto, o artigo procura subsidiar a aproximação do campo da saúde com o do desenvolvimento regional, com foco na região de fronteira, caminhando num sentido duplo: de um lado traz a agenda de desenvolvimento para o campo da saúde e, de outro, fornece pistas de como as ações em saúde podem contribuir para uma perspectiva mais geral de desenvolvimento e integração.

Áreas de Fronteira; Desenvolvimento Regional; Sistemas de Saúde

\section{Referências}

1. Cassiolato JE, Lastres MM. Globalização \& inovação localizada. Brasília: Instituto Brasileiro de Informação em Ciência e Tecnologia, Ministério da Ciência e Tecnologia; 1999.

2. Haesbaert R. O mito da desterritorialização: do "fim dos territórios" à multiterritorialidade. Rio de Janeiro: Editora Bertrand Brasil; 2004.

3. World Health Organization. Macroeconomics and health: investing in health for economic development. Washington DC: World Health Organization; 2001.

4. Gadelha CAG. Desenvolvimento, complexo industrial da saúde e política industrial. Rev Saúde Pública 2006; 40 Especial:11-23.

5. Gallo E, Costa L, Moraes A. A integração dos sistemas de saúde que atendem a população fronteiriça dos países do MERCOSUL - SIS-MERCOSUL. In: Gallo E, Costa L, orgnizadores. SIS-MERCOSUL: uma agenda para integração. Brasília: Organização Pan-Americana de Saúde; 2004. p. 41-53. (Série Técnica - Projeto de Desenvolvimento de Sistemas e Serviços de Saúde 9).

\section{Colaboradores}

C. A. G. Gadelha contribuiu majoritariamente nos temas correlatos à saúde e desenvolvimento, e foi responsável pela supervisão do desenvolvimento e conteúdo do artigo. L. Costa contribuiu majoritariamente nos temas relacionados às políticas de desenvolvimento das fronteiras, assim como pelas críticas à sua implantação.
6. Gallo E, Costa L, Bretas N. Sistema Integrado da Saúde nas Fronteiras: SIS Fronteira e a integração em busca da eqüidade. In: Costa L, organizador. Integração de fronteiras: possibilidades Brasil-Bolívia na saúde. Brasília: Ministério da Saúde/Ministério da Integração Nacional/Organização PanAmericana da Saúde; 2006. p. 41-51.

7. Ministério da Integração Nacional. Política Nacional de Desenvolvimento Regional. http://www. mi.gov.br (acessado em 08/Set/2005).

8. Bandeira OS. Construção das políticas de integração nacional e desenvolvimento regional. In: Ministério da Integração Nacional, organizador. Reflexões sobre políticas de integração nacional e de desenvolvimento regional. Brasília: Ministério da Integração Nacional; 2000. p. 71-138. 
9. Gadelha CA, Costa L. A política nacional de integração e desenvolvimento das fronteiras: o Programa de Desenvolvimento da Faixa de Fronteira - PDFF. In: Oliveira TCM, organizador. Território sem limites: estudos sobre fronteiras. Campo Grande: Universidade Federal do Mato Grosso do Sul; 2005. p. 25-46.

10. Machado LO, organizador. Proposta de reestruturação do Programa de Desenvolvimento da Faixa de Fronteira. Brasília: Ministério da Integração Nacional; 2005.

11. Becker, BK. Reflexões sobre políticas de integração nacional e de desenvolvimento regional. In: Ministério da Integração Nacional, organizador. Reflexões sobre políticas de integração nacional e de desenvolvimento regional. Brasília: Ministério da Integração Nacional; 2000. p. 9-35.
12. Costa L, Cobuccio B, Lins MC, Oliveira ACB. Instrumentos supranacionais e ações internacionais visando à integração de fronteiras. In: Costa L, organizadora. Integração de fronteiras: possibilidades Brasil-Bolívia na saúde. Brasília: Ministério da Saúde/Ministério da Integração Nacional/Organização Pan-Americana da Saúde; 2006. p. 83-106.

13. Gartenkraut M. A gestão do investimento público em infra-estrutura frente ao atual contexto macroeconômico da América do Sul. In: Reunião Técnica sobre Mecanismos de Financiamento. Brasília: Iniciativa para a Integração da Infra-estrutura Regional Sul Americana; 2002. p. 19-25.

14. Câmara de Políticas de Integração Nacional e Desenvolvimento Regional,Ministério da Integração Nacional. Ação integrada de desenvolvimento regional. Brasília: Ministério da Integração Nacional; 2005.

Recebido em 10/Out/2006

Aprovado em 09/Jan/2007 